\title{
Proceeding
}

\section{Proceeding of Certificate Course in Medical Editing at University of Health Sciences Lahore Shireen Jawed}

Lahore: University of Health Sciences (UHS) in collaboration with Pakistan Association of Medical Editors (PAME) has initiated a Certificate Course in Medical Editing with an objective to help build professional capacity of editors of biomedical journals.

This six-month course with two contact sessions of four day each will also enable other healthcare professionals who wish to take up medical journalism as a career or wish to have an additional qualification being interested in scientific publishing. Mr. Shaukat Ali Jawaid Chief Editor, Pakistan Journal of Medical four will consist of a Thesis.

\section{FIRST CONTACT SESSION}

First contact session for the first batch was organized from 4th September 2018 to 7th September 2019. Facilitators in this session included Mr. Shaukat Ali Jawaid, Chief Editor of Pakistan Journal of Medical Sciences, Prof. Jamshed Akhtar Editor of journal of the college of physicians and surgeons Pakistan (JCPSP) and Dr Masood Jawaid (Associate editor PJMS).

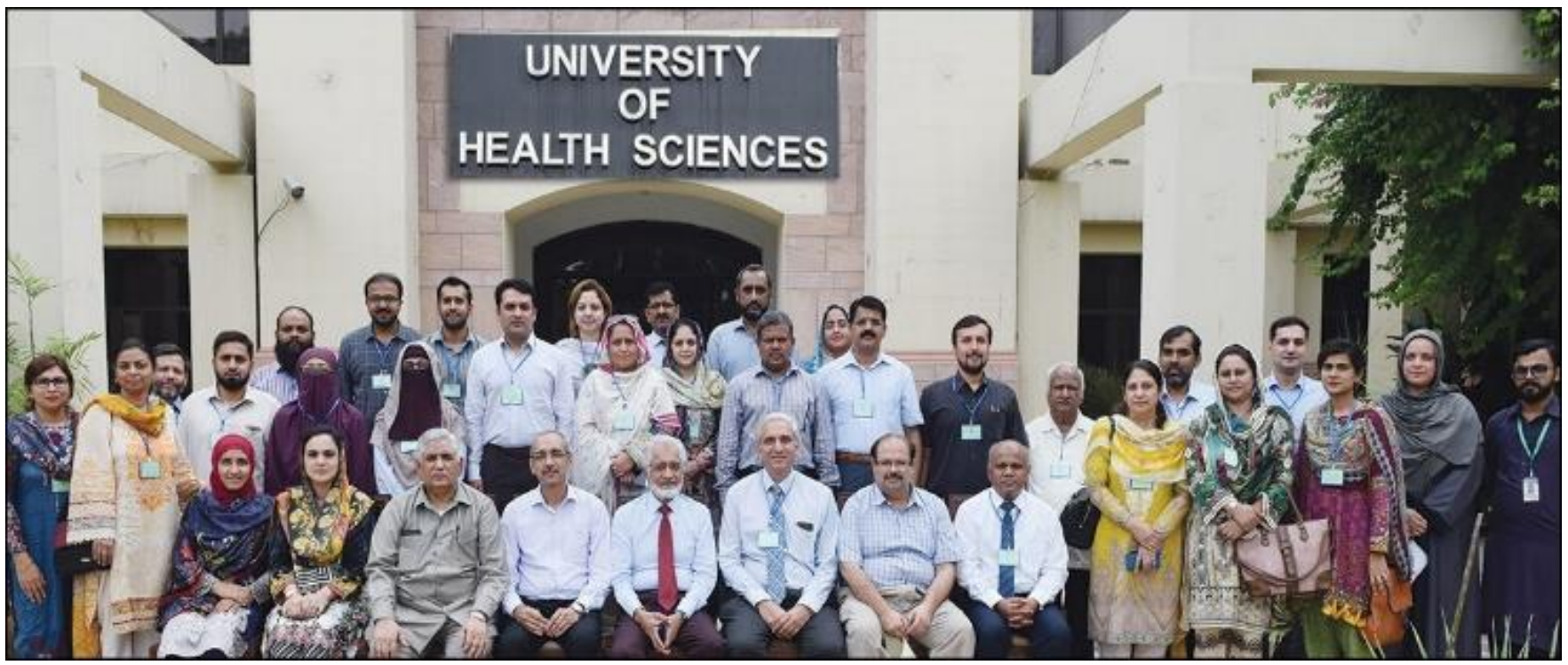

Participants, of the Certificate Course in Medical Editing (First batch) at UHS photographed with VC UHS Prof. Javed Akram,, Course Coordinator Mr. Shaukat Ali Jawaid, President PAME Prof. Jamshed Akhtar and members of the organizing committee.

Sciences (PJMS) who is also Secretary of Eastern Mediterranean Association of the Medical Editors (EMAME) is the course coordinators while over a dozen other distinguished editors from Pakistan, Saudi Arabia and Islamic Republic of Iran are also affiliated with this course as facilitators and mentors. ${ }^{1}$ In fact this is the First Module which will be followed by an Advance Course in Medical Editing Module Two, then Module Three and finally Module Four which will eventually lead to a Master's Degree. All the modules are of six months duration and they include assignment portfolio, final assessment and viva exam while module

\section{Correspondence}

Dr. Shireen Jawed

Email: drshireenjawed@gmail.com
On the first day Mr. Shaukat Ali Jawaid gave a brief introduction of CME course and pointed out its importance and commended the efforts of PAME and UHS for this good initiative for capacity building of editors that could be helpful in uplifting the standards of biomedical journals published from Pakistan. He discussed at length basic principle of medical writing, essential component of an original article which included structure abstract, introduction, methodology, results, discussion and conclusion. He also highlighted the importance of internal review and copy editing. He shared useful tips for initial screening also known as editorial triage, internal review and medial editing. $\mathrm{He}$ stated that look carefully at the title and objectives of manuscript. Make sure that they match each other. During initial screening or internal review one should 
check the manuscript for essential component of an article. Ensure that the structured abstract is in four headings like objective, methodology, results, conclusions and appropriate Mesh key words. Some authors also use background instead of objective but it is better to shift information of background into introduction if not essential, he suggested. A new sentence should not start with figure but write it in words particularly the single digit figures to avoid mixing it with references which should always be in superscript. Follow ICJME guidelines while writing the references by listing up to six authors followed by et al. Make sure that the journal with which you are affiliated, there is uniformity in abstract, references and page numbering in references. The references should be in order i.e. 1,2,3,4 and so on. Any reference can be repeated but make sure that the reference in the text also tally with the reference list at the end. Some authors while revising the manuscript when use Endnote for references, it does create some problem and references are changed. Hence it is always better to check each and every reference in the text that it tally with the reference list manually before final submission. Reference to local studies are a must and make sure that atleast 30$50 \%$ of the references are from the last five years which will increase the chances of acceptance of manuscript for publication. It is essential that the relevant information is included in the appropriate section i.e. introduction, methodology, results, discussion. Discussion is the most important part which should have most of the references as it is here where the authors are supposed to compare their results with other studies locally to national, regional and international studies. It is only possible with proper literature search. As per ICMJE guidelines, summary of review articles must include the time period and the databases searched and number of articles selected for review.

One of the reasons for rejection of manuscripts he stated was inclusion of information in inappropriate section i.e. something which should have come in introduction is included in Methodology and so on. Yet another mistake committed by authors and some editors as well was not making differentiation between patients and methods and material and methods. To avoid all this confusion, it is better that one uses the word Methods or Methodology in abstract as well as text which will cover the studies irrespective of the fact whether it included the patients, healthy subjects of material. He laid emphasis that one should convey the message effectively using simple language and small sentences. Ensure that all tables and figures are described in result, they have proper foot notes, headings and must convey the message in standalone position and readers do not need to read the text.

Later in this session authorship guidelines by ICMJE were also discussed. Roles and responsibilities of medical editors were emphasized along with following professional ethics and ensuring that only those are listed as authors who are eligible and the menace of gift authorship is discouraged.

$\mathrm{He}$ also spoke about editorial freedom, decisions power and contract appointment for editors. Editors should be, honest and never misuse their position. He further pointed out that availability of minimum staff was a pre-requisite for successful publications of journals. He made it clear that editorship is full time stressful job, and it needs a team work. Transparent policy regarding processing fee, publication charges, peer review system how the journal handles scientific misconduct are extremely important and all this information must be included on the journal website which will help the journal in indexation with reputed data bases. Authentication of declaration of publisher and printer from the Government of Pakistan which is issued by the District Magistrate after issuance of No Objection Certificate by the press information department (PID) of ministry of information broadcasting Pakistan was the most important and prerequisite for starting a journal.

Second day was devoted to discussion on provision of constructive unbiased peer review and maintaining quality of publication. This session was facilitated by Prof. Jamshed Akhtar. He emphasized the importance of an effective peer review system while the editors are supposed to review the reviewer's comments before they are forwarded to the authors for revising their manuscripts. Peer reviewer should be subject expert with strong research back ground. Many journals have inexperienced editorial board and lack experienced reviewers. He further stated that quality of the manuscripts published by many inexperienced editors are also questionable. Some journals face paucity of manuscripts. Bypassing the editorial process and publication of article without peer review should be discouraged, he remarked.

He discussed different types of peer review system and said that HEC lays emphasis on double blind peer review system. Further he discussed advantages and disadvantages of open and double blind peer reviews systems. The peer review policy adopted by the journal must be clearly mentioned on journal website. Reviewers should be provided guidelines in the form of a proforma which should be open ended. Reviewer's comments should help the author to improve their 
manuscripts. If the reviewers have some conflict of interest, they should inform the editor and refuse to review the manuscripts. If the reviewer needs some more time, this should also be communicated to the editor. In case of conflict of interest reviewers should inform to editors and refuse to review article. He also emphasized on timely review.

Dr Jamshed Akhtar further pointed out that he has seen some papers in clinical sciences such as pediatrics or surgery where in some of the authors are listed from department of basic sciences who have nothing to do with them. Such unethical practices need to be checked. There was lot of debate on this issue of authorship and at the end it was agreed that now basic sciences are being integrated with clinical sciences from the very beginning hence there is no harm with such authorship but authorship guidelines by ICMJE should be followed. Those who have intellectual, meaningful contribution only those are eligible to be listed as authors. Later on Mr. Shaukat Ali Jawaid discussed different business models for long term sustainability of the medical journals.

On the third day Mr. Shaukat Ali Jawaid shared his experiences. We as editors, he stated, should encourage and guide authors rather than discourage them. One of the common causes of desk rejection of papers is not following the instruction for authors published by journals, he added.

This was followed by the presentation by Dr Masood Jawaid, Who highlighted the importance of digital object identifier (DOI) and networking. This system provides a technical and social infrastructure for the registration and use of DOIs, for use on digital networks, he stated. It is the URL number and object/article identifier. Its important feature is to redirect the objects/articles through handle system. DOI was introduced by International DOI Foundation (IDF) which is ISO certified, he added. He further stated that CrossRef is one of the important regulatory agencies which provide this digital identifier number. Further he added that Extensibility, independence, dynamic updating, multiple resolution, interoperability and class management are the advantages of DOI.

The fourth day of session was facilitated by Mr. Shaukat Ali Jawaid and Dr. Masood Jawaid. Mr. Shaukat Ali Jawaid summarized discussions of previous three days. He stressed on initial screening, internal review, importance of external peer review and eligible authorship. He gave his view about editorship and emphasized on editorial independence of editors. Major part of this session was devoted to open journal system (OJS). He also highlighted various pressures on editors and said that authors were the most dangerous pressure group which the editors have to face as they wish to get their manuscripts published immediately after submission. ${ }^{2}$ Most often the authors demand that they should be provided an acceptance letter while the paper can be published later but little do they realize that an acceptance letter can be issued only once the manuscript has gone through the whole peer review process which takes time and there is no short cut. Some authors wish their manuscripts to be processed on fast track for which they are prepared to pay extra fee but even this facility provided by some journals is not available all the time. While doing post acceptance editing, one might come across some deficiencies which have to be rectified. Sale and purchase of the authorship and gift authorship is quite common which are a challenge for the editors. To avoid the possibility of any error in published article, PDF file should be sent to the authors prior to publication for proof reading. Some authors do not know how to make corrections, instead of making corrections in PDF files they make correction in their original submitted files which creates more problems for editors. Moreover, some journals publish the corrected final manuscript ahead of print on the journal website which provides another opportunity to the authors to see if all the corrections they had marked have been carried out and if not, they can point it out and get it corrected. Incomplete submissions and lack of required documents including ethical approval and signed undertaking form by all the listed authors is yet another common reason for desk rejection, he stated.

During discussion the issue regarding publication of manuscripts by the editors in their own journals was also raised. Some participants pointed out that some regulatory bodies require that, editors should not publish his/her own article in their journals. Mr. Shaukat Ali Jawed remarked that there was no harm in publishing in one's own journal but it must go through the proper peer review system.

Dr. Masood Jawaid demonstrated all aspects of the open journal management system (OJS). He demonstrated about the setting for journal, sending submitted article for review and communication with authors by OJS. OJS offers many advantages, he stated. He emphasized to use journal management system for transparent processing of submitted articles to medical journals. All participants also had hands on practice on OJS at the end of the session under supervision Dr Masood Jawaid.

\section{SECOND CONTACT SESSION}

The second contact session also comprised of four 
days from $11^{\text {th }}$ December to $14^{\text {th }}$ December 2019. First day session was facilitated by Mr.Shaukat Ali Jawaid. In his informal talk he emphasized the importance of spreading, sharing knowledge. $\mathrm{He}$ quoted late Major Gen. Mohsin Pal former Director General of Health who while speaking at the formal launching ceremony of book on Medical Writing authored by Mr. Shaukat Ali Jawaid had remarked that "Knowledge flows to those who are capable of receiving it, respecting it, protecting it, preserving it and promoting it." He gave feedback about assignments of CME candidates and guided them about the contents of their portfolio.

An interesting part of that session was the discussion concerning the reporting of adverse drug reactions (ADR). He highlighted the importance of reporting ADR and described the facts responsible for not reporting and publishing adverse reaction in Pakistan. He said that many of the Pakistani medical journals are dependent on advertising from the pharma trade and industry hence; most of them do not want to highlight or publish the adverse reaction of their drugs, which could affect their sales.

On the other hand, in some clinical trials they wished to publish only favorable results of these trials. Another possible cause of failure of reporting ADR is ignorance by doctors, he opined. Many juniors doctors lack clinical skills and do not monitor adverse reaction. Some senior doctors are also not reporting the ADR due to their ignorance or cordial relations with pharmaceutical companies and don't want to lose benefits/ privilege they enjoy. He further described the role of editors in publishing ADR. He suggested publishing ADR after peer review; one can also ask the pharmaceutical company concerned to provide if they have any post marketing surveillance reports related to those drugs. Professional ethics demand that company's view point should also be published along with the response from the author. ADR is important for patient's safety and care. He advised editors to understand their duty concerning reporting ADR, publish it after ensuring transparency, clinical relevance and credibility of report. The important three functions of the press, he further stated, are to inform, educate and guide. All these require different level of professional expertise. He stressed that there are some well-known professional competencies for the Editors. ${ }^{3}$ Journalist/editors must keep their knowledge updated, as the ignorant journalists could be harming the society by spreading the wrong information.

In last part of the session, he discussed the role of medical editors in improving the patient care through research. He highlighted the functions of medical editors and emphasized to update their knowledge as their role is not only accepting or rejecting the article but they have to teach and guide the authors. Editors have pivotal role in highlighting public health problems and improving patient's safety. They have role in promoting the ethical practices in health sectors. He then shared his personal experience how he picked up the idea of working on diabetic foot to improve its care in Pakistani patients, wrote an editorial highlighting the plight of diabetic foot patients. This eventually resulted in the establishment of the First Diabetic Foot Clinic at Baqai Institute of Diabetes and Endocrinology at Baqai Medical University (BIDE) at Karachi. Later BIDE under the leadership of Prof. Abdul Basit helped establish numerous diabetic foot clinics all over the country helping improve diabetic foot care in Pakistan which also reduced the amputation rate by almost $50 \%$, he added.

Dr Fatema Jawad chief editor of Journal of Pakistan Medical Association was the facilitator on second day of this contact session. She spoke about publication misconduct and discussed various flow charts prepared by Committee on Publication Ethics of UK (COPE) and its guidelines related to problems faced by editor. In next part of her presentation she described the various types of scientific misconducts including falsification, fabrication and plagiarism. Types of the plagiarism she mentioned included word to word, mosaic model, paraphrasing without giving the references and image manipulation. She urged the participants to avoid image manipulation as it can also change the results. She further stated that authors must avoid plagiarism because when caught; it leaves a bad impression, not only results in rejection of an article and might be retracted even after publication.

She also emphasized the importance of avoiding duplicate submission as well as publications which can be prevented by ensuring that all authors listed on the manuscript have singed the undertaking Form. She also suggested avoiding falsification, fabrication, salami slicing and redundant publications etc. She then discussed various case stories related to falsification and fabrication, and their consequences.

She also talked on conflict of interest which could be due to personal relationships, honoraria, financial relationship, relationship with industries and academic competitions. She was of the view that it is the moral duty of seniors to educate their juniors for the ethical writing to preserve integrity and accountability of the research. She further added that many authors indulge in scientific misconduct for their promotions and getting degrees but it is unethical and the regulatory bodies can take serious action which could be in the 
form of removal from the job, demotion thereby putting their whole academic career at stake.

She suggested that journals should have transparent policies to deal with the publication misconducts and it should be available on journal websites. Every journal must have software like iThenticate or TurnitIn for detecting plagiarism and follow COPE guidelines for publication ethics.

Dr. Saira Afzal Editor of Annals of KEMU was one of the speakers on the third day of this contact session. She described the success story of the Annals of King Edward Medical University (AKEMU). She said that
Clarivate Analytics, Medline, PubMed, Index Medicus, Directory of Open Access Journal (DOAJ), PubMed central and Scopus etc. Availability of articles on various databases will make it visible and easily searchable which enhance the readership and citations, she added. She also highlighted the importance of a good peer review system for ensuring quality of manuscripts accepted for publication. She suggested to have separate web sites for the journals from the institutional websites and use of open journal system for processing the manuscripts. She further stated that the use of OJS and regular timely publication are

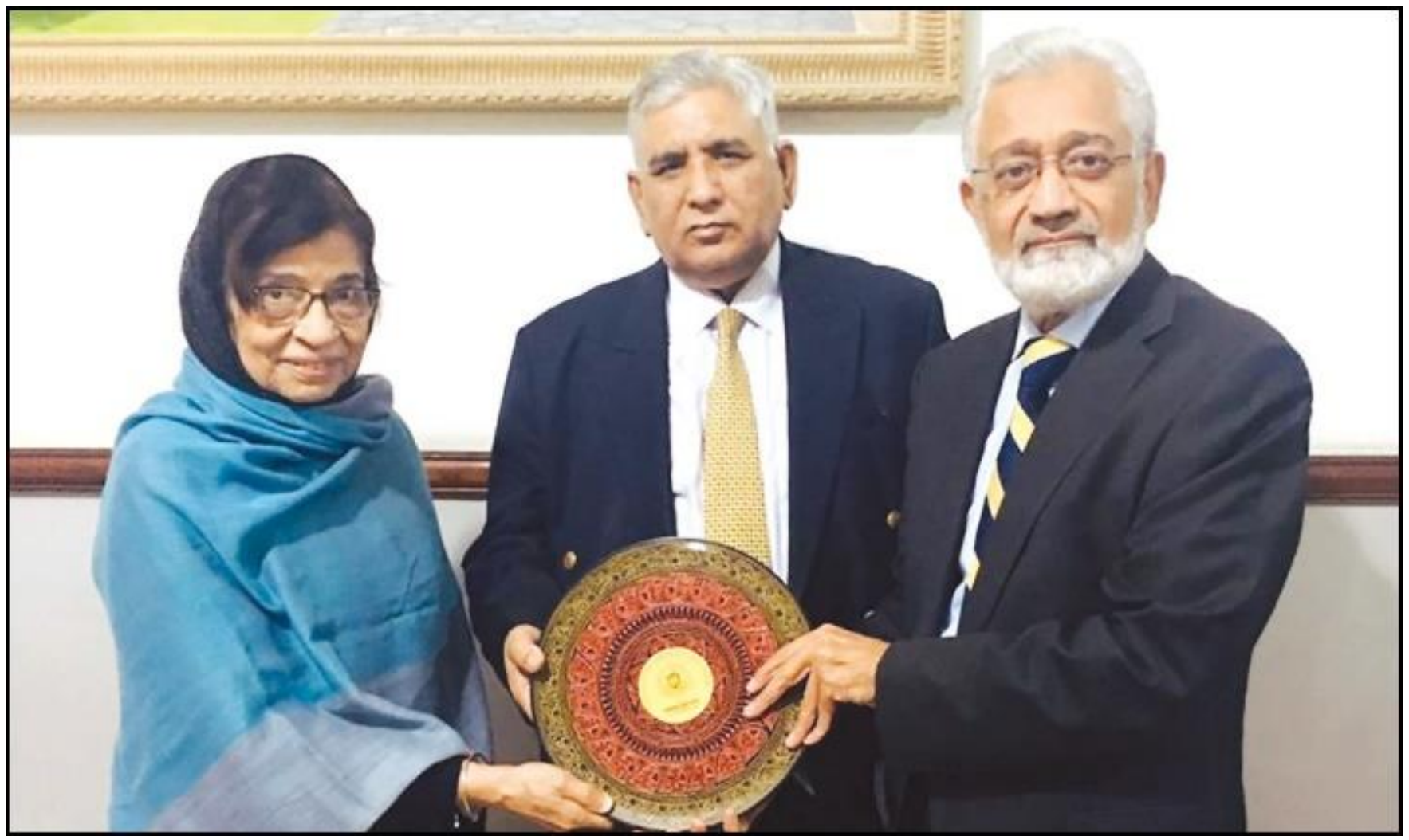

Prof. Javed Akram Vice Chancellor UHS presenting a memento to Dr. Fatema Jawad Editor-in-Chief of JPMA.Mr. Shaukat Ali Jawaid Chief Editor of Pakistan Journal of Medical Sciences and Coordinator of the Course is in center

for AKEMU she was lucky to be selected as a recipient of Dr. Maqbool H. Jafary Training scholarship started by Mr. Shaukat Ali Jawaid in memory of their late Founder Chief Editor. She appreciated his efforts in medical journalism and training of young editors to uplifting the standards of medical journals of Pakistan. Mr. Shaukat Ali Jawaid always highlighted problems faced by medical journals of Pakistan in different forums including regulatory bodies, she remarked. At Annals of KEMU we practice double blind peer review system she stated. She moreover briefly referred to indexation of journals by various databases like mandatory for recognition of journals by regulatory bodies. She emphasized to maintain the archives of previous at least ten years published issues of journals on web site, as it will increases the citation of journals which can be checked through Google Scholar. She guided editors to get membership of professional associations such as Pakistan Association of Medical Editors(PAME), World Association of Medical Editors (WAME) and Eastern Mediterranean Association of Medical Editors (EMAME). She opined that various editorial board members of the journal should write editorials, instead of one person writing editorial for 
every issue. She appreciated efforts of IT departments of King Edward Medical University (KEMU) which has played a vital role in success of AKEMU. She introduced the Quick response (QR) code generated by IT department of KEMU, used for tracing citations of AKEMU.

Later Mr. Shaukat Ali Jawaid, talked about the role of media in spreading the knowledge and how to deal with media personnel. During his talk he pointed out that the media has important role in spreading the correct information and educating the society on various issues including problem related to health. $\mathrm{He}$ also expressed his views about the role of science in health and environment and spreading this knowledge by media. Media personnel, he emphasized should have core knowledge about the subjects. They must avoid the dissemination of wrong information, which could be harmful for society. He pointed out that in Pakistan the owners of media houses seldom hire the journalist with core knowledge and are spreading the incorrect information. He suggested that professional specialty organizations should educate the media personnel. He shared various examples of incorrect reporting by the media and their harmful effects. He said that the media can act as translator and gate keeper to play positive role in spreading correct information. They can simplify scientific knowledge which can also be easily comprehended by lay man. He encouraged developing good relations with media personnel to convey the correct message to society. He also talked about the social media, blog, and twitter. He further opined that the media can play its positive role in spreading the knowledge about the health related problems and common diseases. He explained that various telefilms, dramas and talk shows can easily create awareness about common diseases and important health issues. However, the scientists and medical profession should have communication strategies with media personnel. He laid stress on self-monitoring of medical as well as media professionals to avoid the mishaps and they should play positive role in betterment of society. There is need to fill the communication gap between the medical and media professionals for creating awareness of the community related health problems.

Last and the fourth day of $2^{\text {nd }}$ contact session was facilitated Prof. Dr. Akhter Sherin Chief Editor Khyber Medical University Journal. He also has an important role and contributions for the enhancement of medical journalism. He discussed authorship criteria laid down by ICJME guidelines. This was an excellent debate clearing all concepts regarding authorship. The salient features of the ICMJE guidelines on authorship, he stated, were:
- interpretation of data for the work; AND Substantial contributions to the conception or design of the work; or the acquisition, analysis, or

- Drafting the work or revising it critically for important intellectual content; AND

- Final approval of the version to be published; AND

- Agreement to be accountable for all aspects of the work in ensuring that questions related to the accuracy or integrity of any part of the work are appropriately investigated and resolved.

He pointed out that many authors are unaware of this guideline causing authorship issues. He discussed the differences between the authorship and non-author contributors. All those who help in conducting the study but do not fulfill the ICMJE four criteria to be eligible to be listed as authors should be covered in acknowledgment. He suggested that all those who have helped in the conduct of study should also be acknowledged. Supervisors, those who helped only in securing funding, other colleagues who have helped in study design, lab assistants should be acknowledged, he stated. Statisticians without significant contributions are not eligible to be listed as authors. Supervisor can be included in authorship,if he/she has made significant contribution. ${ }^{5} \mathrm{He}$ stressed that supervisors should not be the 1st author. First author should be the one who has actually done the study or has major contribution in the study. Mr.Shaukat Ali Jawaid pointed out that acknowledgment is considered as an endorsement of the study findings that is why now it is being discussed at different forums that authors should be asked to provide written permission from those who are being acknowledged. This is still under discussion and no final decisions have been taken so far, he stated.

Prof. Akhtar Sherin then talked about the gifted and ghost authorship. Authorship granted to those who are not full filling ICJME criteria is gifted authorship. Many authors include the names of their seniors in respects or head of their department, institution just to increase the chance of publication comes in the category of gift authorship. ${ }^{4}$ The author who full fill the criteria of authorship but not included in the authorship list or author hired purely for the purpose of writing but not acknowledged are ghost authorship, he remarked. Later on various problems faced by editors concerning authorship were discussed. He also referred to the addition or removal of thr author's name from article before and after publications which was followed by lively discussion by the participants. In last session, Prof. Akhtar Sherin discussed about systematic review, meta-analysis and narrative review. He pointed out that the systematic review and meta-analysis have 
major role in making guidelines. Randomized control trials are also useful for making guidelines. He also referred to the PRISMA guidelines for meta-analysis. At the end test was taken based on different scenarios. In the end of session Mr. Shaukat Ali Jawaid in his concluding remarks appreciated the whole batch of CME. He hoped that all the participants will work hard for the improvement of their journals making use of the information they have got during the course.

\section{CONCLUSION}

Throughout the course (first and second contact sessions), participants of CME learned editorial triage, how to edit manuscript, cross checking of references, recognize plagiarism and scientific misconducts. They learned about the different peer review systems. How to communicate with authors, reviewers, and editorial board members was discussed in detail which will be extremely useful for the participants. Overall, this course was intellectually satisfying and strengthens critical cognition skills of the participating editors.
Editors of various journals who participated in this course will be in a better position to critically analyze the submitted manuscripts. They would be able to recognize and take decision about different types of misconduct. This all became possible because of guidance and encouragement of course facilitators and mentors.

\section{REFERENCES}

1. Certificate in Medical Editing. http://www.uhs.edu.pk/ cme.php.[cited on: Oct 27, 2020].

2. Jawaid SA. Problems faced by editors of peer reviewed medical journals. Saudi Med J. 2004;25, Suppl 1.pp 447-451.

3. Jawaid SA, Jawaid M. Professional competencies required for Editors of Biomedical Journals. Pak J Med Sci.2017;33(5):10 50-1052.doi:10.12669/pjms335. 13967

4. Jawaid SA, Jawaid M. Some useful tips to detect Gift Authorship. Pak J Med Sci. 2020 ; 36 (6) : 1145-1146 doi:https://doi.org/10.1 2669/pjms.36.6.3154

5. International committee of Medical Journal Editors.Recommendations for the Conduct, Reporting, Editing and publication of scholarly work in Medical Journals. available from: http;/www.ICMJE.org.[cited on : Oct 27,2020] 